\title{
Heat Capacities and Related Thermal Data for Diethyl Phthalate Crystal, Glass, and Liquid to $360{ }^{\circ} \mathrm{K}$
}

\author{
S. S. Chang, J. A. Horman, ${ }^{*}$ and A. B. Bestul \\ Institute for Materials Research, National Bureau of Standards, Washington, D.C. 20234
}

(Marcb 28, 1967)

\begin{abstract}
Experimentally determined heat capacity values, precise to within 0.1 percent, and related thermal data are reported for quenched and annealed diethyl phthalate glasses from $10^{\circ} \mathrm{K}$ to the glass transformation temperature, $T_{g}$ (around $180{ }^{\circ} \mathrm{K}$ ), for the liquid from $T_{g}$ to $360{ }^{\circ} \mathrm{K}$, and for the crystal from $10{ }^{\circ} \mathrm{K}$ to the melting temperature $\left(269.9^{\circ} \mathrm{K}\right)$. The mole fraction of liquid-soluble, solid-insoluble impurity in the sample as determined by fractional melting was 0.0012 . Common thermodynamic properties calculable from the experimental data are reported. The heat capacities of the two glasses differ by more than the uncertainty of the measurements, and both lie below that of the crystal in the range from 30 to $75^{\circ} \mathrm{K}$. At low temperatures, just above $10^{\circ} \mathrm{K}$, the heat capacities of the glasses rise as much as 8 percent above that of the crystal.
\end{abstract}

Key Words: Annealed glass, crystal, diethyl phthalate, glass transformation, heat capacity calorimetry, molecular configurational state, normal and supercooled liquid, quenched glass, residual (configurational) entropy, thermodynamic properties.

\section{Introduction}

The crystallization process in diethyl phthalate is conveniently controllable. Crystallization can easily be avoided and the liquid cooled to the glass by convenient procedures. By different convenient procedure s the crystal can easily be formed. This controllability makes diethyl phthalate a convenient substance on which to perform studies in the crystalline, liquid, and vitreous conditions. The relations between the properties in these three conditions are important especially to progress in understanding the glassy condition.

This paper reports precision heat capacity and related thermal measurements on diethyl phthalate glasses from $10{ }^{\circ} \mathrm{K}$ to the glass transformation temperature, $T_{g}$ (around $180{ }^{\circ} \mathrm{K}$ ) on the liquid from $T_{g}$ to $360{ }^{\circ} \mathrm{K}$, and on the crystal from $10{ }^{\circ} \mathrm{K}$ to the melting point $\left(269.9{ }^{\circ} \mathrm{K}\right)$. The results provide suggestive, explanatory, or confirmatory information on several questions concerning thermodynamic relations for glasses.

\section{Experimental Detail}

\subsection{Calorimetry}

The measurements reported here were performed in the low-temperature adiabatic precision calorimeter described in reference [1]. ${ }^{1}$

\footnotetext{
*Present address: 4506 Andes Court, Fairfax, Va. 22039.

${ }^{1}$ Figures in brackets indicate the literature references at the end of this paper.
}

At temperatures below $12{ }^{\circ} \mathrm{K}$, however, the NBS1955 provisional temperature scale cited in reference [1] was not used. Rather a temperature scale (hereafter referred to as the $2-5$ scale) was used which was based partly on the observed resistance of the calorimeter's resistance thermometer at the boiling temperature of helium. An equation of the form $R=C_{0}+C_{2} T^{2}+C_{5} T^{5}$, where $R$ is resistance, $T$ is temperature, and the $C$ 's are constant coefficients, was fitted to this observed resistance at the helium boiling temperature and to the resistance and temperature derivative of resistance given for $12{ }^{\circ} \mathrm{K}$ by the NBS-1955 provisional temperature scale calibration of the resistance thermometer. The $2-5$ scale was used rather than the NBS-1955 scale at temperatures below $12{ }^{\circ} \mathrm{K}$ because the lowest temperature of calibration of the resistance thermometer against the NBS-1955 scale was $11.42^{\circ} \mathrm{K}$, and the extrapolation of this calibration to lower temperatures showed an inconsistency with the observed resistance (considered correct) of the thermometer at the boiling temperature of helium. The establishment of the 2-5 scale will be described more fully in a subsequent publication on the heat capacities of arsenious oxide. The heat capacities used in the present paper for the empty calorimeter at temperatures below $12{ }^{\circ} \mathrm{K}$ were also recalculated on the basis of this $2-5$ scale.

Calculations of heat capacity values from measurements on the glass in the glass transformation range of temperature (where the molecular configuration changes with time) were performed in the manner 
described below. This procedure was directed at yielding the heat capacity of the glass in a definite state in which the molecular configuration is fixed at that existing at the midtime of the calorimetric heat input. To do this the extrapolation of calorimetrically observed temperatures to the midtime of a heat input is based on observed temperature drifts which include observable contributions from configurational change (configurational drift) as well as from heat transfer between the calorimeter and its environment.

This procedure is distinctly different from an alternative one often used. According to this alternative procedure the drift of temperature of the calorimeter between heat inputs is observed for a period of time sufficiently long so that the configurational contribution decreases to a level below the limit of observability. Then the extrapolation to the midtime of a heat input is based on drift rates which presumably arise only from heat transfer between the calorimeter and its environment.

Initial and final temperatures obtained in this alternative manner for a given heat capacity determination apply to different configurational states of the experimental substance. However, these states are still not the equilibrium supercooled liquid states. If they were, the resulting heat capacity value would apply unequivocally to the equilibrium supercooled liquid. In the transformation region, where no equilibrium configuration is attained however, so-called heat capacity values determined according to this alternative procedure do not apply to any definite state of substance.

In the transformation region the heat capacity values reported in this paper for successive temperatures in a given measurement series should apply to glasses of progressively aifferent, but definite configurations.

In principle our procedure has the disadvantage that once the experimental data are reduced to a heat capacity versus temperature relationship, the temperature integral of the heat capacity may not give accurate values of the enthalpy change through the glass transformation region. This is because, for reasons explained below, the glass transformation temperature $\left(\mathrm{T}_{g}\right)$ value indicated by the heat capacity curve is not necessarily characteristic of the glass that existed at temperatures well below the transformation region and to which the main body of heat capacity data apply.

The $T_{g}$ value indicated by the heat capacity curve is usually taken as that of the midpoint of the heat capacity rise from the value for the glass to that for the liquid. This value is characteristic of the glass that exists at that time, when the configurational relaxation times for the existing glass become short enough to allow configurational equilibration within the experimental time scale. However, the molecular configurations in the glass also change slowly but incompletely during passage through the lower temperature part of the transformation range. Therefore, the configurational state corresponding to the indicated $T_{g}$ value is different from that of the glass that existed at temperatures well below the transformation region. This means that the heat capacities used in the enthalpy integration may change from the (lower) values for the glass to the (higher) values for the liquid at a temperature other than that which yields the correct enthalpy difference between the liquid and the glass that existed well below the transformation region. The indicated $T_{g}$ can be either too low or too high depending on whether, and to what extent, the glass is either quenched or annealed.

The same displacement of $T_{g}$ is equally possible when heat capacities are calculated according to the alternative method mentioned above. However, in this case the temperature integral of heat capacity yields a correct enthalpy difference. This is because each heat capacity value includes the heat effect which accompanies the configurational change that occurs during the determination, even though the initial and final configurations may be unspecified. It is this inclusion that prevents these heat capacity values from representing any definite configurational state.

We have chosen to present heat capacity values which represent definite configurational states, but whose integral may not yield valid enthalpy changes rather than values whose integral yields valid enthalpy changes, but which do not represent definite configurational states. This choice is important in situations involving quantitative use of $\Delta C_{p}$, the difference in heat capacity between the glass and the liquid. Valid enthalpy changes are obtained here by summing over the entire transformation range the energy inputs for all the heat capacity determinations made in the range in a given series, assuming perfect adiabaticity in calorimetric conditions. These enthalpy changes are checked by comparing results from different series containing different numbers of determinations, and from continuous heating through the entire transformation range.

Calorimeter temperature drifts including configurational contributions are sometimes nonlinear. The functional relation of configurational drift rate to temperature, time, configurational state and deviation from equilibrium has not yet been established in an analytical fashion. Therefore in our heat capacity calculations we have performed the necessary extrapolation of nonlinear drifts by graphical methods. The uncertainty introduced by this procedure cannot always be evaluated.

Such uncertainty is not necessarily responsible for the high points to be observed in the heat capacity curve for the annealed glass at the highest temperatures in the transformation region. Such high points can occur with formally valid extrapolations for one special point in each measurement series. This occurs when the initial temperature of a determination is still in the transformation region, but the final temperature is in the equilibrium supercooled liquid region. In this case the resulting peak point does not represent either fixed molecular config- 
urations or equilibrium molecular configurations, but is a kind of hybrid.

Once a valid enthalpy-temperature plot has been established for a given glass, this can be used to obtain a $T_{g}$ value that is characteristic of the configurations fixed in the glass at temperatures well below the glass transformation range.

Measurements were made of heat of tusion by fractional melting, and by continuous melting. The fractional melting data also yield values for melting point and for liquid-soluble, solid-insoluble impurity.

\subsection{Preparation of Sample}

Commercial diethyl phthalate was purified $^{2}$ by fractional distillation at a pressure of $20 \mathrm{~mm} \mathrm{Hg}$ in a spinning-vane type column having a theoretical plate number around 100 . The distillate was collected at a rate of about $2.5 \mathrm{ml} / \mathrm{hr}$ with a reflux ratio of $1: 30$.

Gas chromatograms obtained with a silicone oil absorption column and a flame ionization detector for the middle fractions from the distillation often indicated a small initial shoulder on the main peak with a ratio of peak heights on the order of 1:2,000. The original material however showed only a much earlier separate peak.

Chemical analysis indicated a composition of 65.0 percent $\mathrm{C}$ and 6.4 percent $\mathrm{H}$ (theoretical values of $\mathrm{C}_{12} \mathrm{H}_{14} \mathrm{O}_{4}$ are $\mathrm{C}: 64.85$ percent and $\mathrm{H}: 6.35$ percent). Determination of water content by the Karl Fisher method indicated 0.005 percent.

Fractional melting data from the calorimetric measurements indicated the presence of 0.0012 mole fraction of solid-insoluble, liquid-soluble impurities.

The calorimetric sample weighed $112.575 \mathrm{~g}$. Using a molecular weight of 222.243, this corresponds to 0.506540 moles. The above weight was obtained as the difference between the weight of the loaded and of the empty calorimeter measurement cell. During these weighings the cell was disconnected from the calorimeter assembly, the cell top was soldered in place, and the filling tube was open. The weighings were performed by double weighing in a kilogram capacity analytical balance designated as NBS 3245. The total weight of the loaded cell was about 390 g. Class S-2 calibrated weights designated NBS 3246 were used. The sample weight was adjusted for air buoyancy using $1.123 \mathrm{~g} / \mathrm{cm}^{3}$ as the density of diethyl phthalate, $8.40 \mathrm{~g} / \mathrm{cm}^{3}$ as the density of the brass weights, and $0.00120 \mathrm{~g} / \mathrm{cm}^{3}$ as the density of air.

\subsection{Physical States of Sample}

An important feature of the results reported in this paper is the comparison of the data for diethyl phthalate in the different physical forms. Therefore, we give here some description of the procedures by which these forms were established for the reported measurements.

\footnotetext{
${ }^{2}$ This purification was performed by R. Leslie of the NBS Analysis and Purification
} Section

\section{a. Liquid}

At reported temperatures above the melting point the liquid exists as the unique form (the vapor pressure being negligibly small), so measurements at these temperatures are unequivocally on the liquid form. At temperatures below the melting point and above the glass transformation temperature, $T_{g}$, measurements can be made on the (equilibrium supercooled) liquid form only if crystallization is completely avoided. This can be accomplished for diethyl phthalate by using two different procedures for two sections into which this temperature range must be divided. If the liquid is heated to a temperature well above the melting point, say to $360^{\circ} \mathrm{K}$, and then cooled to a temperature below the melting point but not below $220^{\circ} \mathrm{K}$, it may be reheated to the melting point without the occurrence of crystallization. Measurements on the supercooled liquid in the range from $22{ }^{\circ} \mathrm{K}$ to the melting point are made in this manner. If the liquid is cooled to or below $T_{g}$ and then reheated, crystallization will commence around $210-220^{\circ} \mathrm{K}$, but not below this temperature. Measurements on the supercooled liquid in the range from $T_{g}$ to $220^{\circ} \mathrm{K}$ are made in this manner.

The classical interpretation of this behavior is that homogeneous crystal nuclei form in the liquid only at temperatures below $220^{\circ} \mathrm{K}$. Therefore, if existing nuclei are destroyed by heating well above the melting point, crystallization will not occur if the temperature is maintanied above $220^{\circ} \mathrm{K}$. However, crystal growth upon existing nuclei apparently does not occur at temperatures below $210{ }^{\circ} \mathrm{K}$. Therefore, if the liquid is held at temperatures below $210{ }^{\circ} \mathrm{K}$ crystallization will not occur even if nuclei are present. This interpretation applies to crystallization based on homogeneous nucleation. That fact that crystal growth does not occur in the well-melted liquid unless it has been previously cooled below $220{ }^{\circ} \mathrm{K}$ suggests that heterogeneous nuclei were not present to an effective extent in the sample concerned here.

The absence of crystals from the equilibrium super-cooled liquid on which measurements are reported here is demonstrated by the heat capacity results for the liquid in the vicinity of the melting point. No heat capacity peak associated with the melting of any crystals is observed. We may cite an exaggerated experimental uncertainty of 0.1 percent in the heat capacity value around 355 joule per degree and mole for the liquid near the melting point; a heat of fusion around 18,000 joule per mole and a melting range around $10^{\circ}$. These figures lead to a value of 0.02 percent as the upper limit on the fraction of crystal which could be present in the supercooled liquid without being detected by the effect of the heat evolved in its melting upon the heat capacities of the liquid near the melting point.

\section{b. Crystal}

To crystallize the sample the liquid is cooled below $220^{\circ} \mathrm{K}$ and then rewarmed to that point, around which 
crystallization commences. Under adiabatic conditions the latent heat of fusion evolved warms the crystallizing sample further, with maximum crystallization rate (as indicated by rate of temperature rise) being reached around $245^{\circ} \mathrm{K}$. Complete crystallization raises the temperature to about $260{ }^{\circ} \mathrm{K}$. The major part of the crystallization, occurring between 225 and $260{ }^{\circ} \mathrm{K}$, requires less than an hour; however, the sample is allowed several hours after this for the completion of the last traces of crystallization. The completeness of crystallization in the samples for which crystal heat capacities are reported here is demonstrated by the heat capacity results for the crystal in the vicinity of $T_{y}$. No heat capacity shift corresponding to the transformation of any glass is observed. The heat capacity of the crystal near $T_{g}$ is around 200 joule per degree and mole with a claimed experimental uncertainty of 0.1 percent. The change in heat capacity in going from pure glass to pure liquid is 115 joule per degree and mole. Assuming a simple additivity, these figures lead to a value of 0.2 percent as the upper limit on the fraction of uncrystallized material which could be present in the crystal without being detected by the effect of its heat capacity shift at $T_{g}$ on the measured heat capacity.

$$
\text { c. Glasses }
$$

Glassy conditions are produced by three different kinds of procedures: (i) quenching, i.e., fast cooling; (ii) rate annealing, i.e., slow cooling; and (iii) soak annealing, i.e., thermostatting for an extended time at a temperature in the glass transformation range.

Quenched glasses were produced starting with the liquid sample in the calorimeter cell at about $350{ }^{\circ} \mathrm{K}$ and insulated thermally by the cryostat vacuum from solid nitrogen at about $50{ }^{\circ} \mathrm{K}$ in the refrigerant Dewar. Thermal conduction was then established between the sample and the solid nitrogen by breaking the cryostat vacuum with helium gas and cooling of the sample commenced. The temperature of the sample was thus lowered to about $50{ }^{\circ} \mathrm{K}$ in a few hours. The rate of cooling of the sample in the glass transformation region (just below $180{ }^{\circ} \mathrm{K}$ ) was at least $2.5^{\circ}$ per minute.

Rate annealed glasses were produced starting with the liquid sample in the calorimeter cell thermostatted by the controlled adiabatic shields at about $200{ }^{\circ} \mathrm{K}$ inside the evacuated cryostat can surround by liquid nitrogen. The heat supply to the adiabatic shields was cut off and unavoidable heat loss through the insulating cryostat vacuum and electrical supply wires slowly cooled the shields and subsequently the cell and sample. In this manner the temperature of the sample was lowered to around $170{ }^{\circ} \mathrm{K}$ overnight. The rate of cooling in the glass transformation range was around $1^{\circ}$ per hour. Subsequent cooling below the glass transformation temperature range was done by breaking the insulating cryostat vacuum with helium gas, and proceeded at rates on the order of degrees per minute.

Soak annealed glasses were produced starting with either quenched or rate annealed glasses. These initial glasses are then maintained for extended periods of time at fixed temperatures in the glass transformation range. For this purpose the calorimeter cell containing the sample under treatment is thermostatted using the controlled adiabatic shields inside the evacuated cryostat can surrounded by liquid nitrogen. The specific temperatures and times for which samples used in particular determinations were held are given in table 1 . The series identification of the samples will be explained in section 3 .

TABĹ 1. Soak annealing schedules

\begin{tabular}{|c|c|c|}
\hline Series & $\begin{array}{c}\text { Soaking } \\
\text { temperature, }{ }^{\circ} \mathrm{K}\end{array}$ & $\begin{array}{l}\text { Soaking } \\
\text { time }\end{array}$ \\
\hline $\mathrm{XX}$ & 181 & $2.5 \mathrm{hr}$ \\
\hline $\mathrm{XXX}$ & 162 & 2 weeks \\
\hline XXXI & $(\mathrm{XXX}+) 169$ & 6 days \\
\hline $\left.\begin{array}{l}\text { XXXII } \\
\text { XXXIII }\end{array}\right\}$ & $(\mathrm{XXXI}+) 173$ & 3 days \\
\hline XLI & 170 & $16 \mathrm{hr}$ \\
\hline XLIV & $\begin{array}{c}160 \\
+170\end{array}$ & $\begin{array}{l}2 \text { days } \\
1 \text { day }\end{array}$ \\
\hline
\end{tabular}

\section{Results}

The heat capacity results are listed in table 2 and their overall graphical presentation is shown in figure 1. In table 2 the heat capacities are grouped first according to the different physical forms for which data are reported. For each physical form the data are grouped in numbered series of successive measurements. These series are numbered according to their chronology in the entire set of measurements on diethyl phthalate, irrespective of physical form. The chronology of the entire set of measurements can therefore be followed, if desired, by following the numbers of these series. If a series covers a transformation from one physical form to another, parts of the series appear under each of the two physical forms. For each physical form, the series are ordered in table 2 in increasing temperature of the first member.

The vapor pressure of diethyl phthalate at $360{ }^{\circ} \mathrm{K}$ is less than $0.2 \mathrm{~mm} \mathrm{Hg}$ [2]. The corresponding correction from $C_{\text {obs }}$ to $C_{\mathrm{p}}(\mathrm{p}=1 \mathrm{~atm})$ is about 0.002 percent of the value, and thus is disregarded.

The absence of crystals from the glass samples on which measurements are reported here can be demonstrated directly only for samples for which heat capacities were measured around the melting point for the liquid formed by heating the sample through the glass transformation range. Since the crystalline content of a sample can increase but not decrease at equilibrium supercooled liquid temperatures, the possible crystallinity thus allowed for the liquid sample serves as an upper limit for that of the glass sample from which the liquid sample was formed. This value is around 0.02 percent as explained earlier. For glass samples for which the above type of data is not obtained, limits on the crystallinity can be obtained by comparison of heat capacity results with samples for which such data are available. These comparisons 
TABLE 2. Heat capacity data for diethyl phthalate (Units in ${ }^{\circ} \mathrm{K}$. joule and mole)

CRYSTAL

\begin{tabular}{|c|c|c|c|c|c|}
\hline$T$ & $C_{p}$ & - $T$ & $C_{p}$ & $T$ & $C_{p}$ \\
\hline \multicolumn{2}{|c|}{ Series XXVI } & \multicolumn{2}{|c|}{ Series X } & \multicolumn{2}{|c|}{ Series XXXV } \\
\hline \multirow{5}{*}{$\begin{array}{l}10.26 \\
11.32 \\
12.66 \\
14.11 \\
15.65 \\
17.40 \\
19.30\end{array}$} & \multirow{5}{*}{$\begin{array}{r}6.28 \\
7.95 \\
10.14 \\
12.56 \\
15.47 \\
18.82 \\
22.48\end{array}$} & \multirow{5}{*}{$\begin{array}{r}87.58 \\
95.58 \\
104.54 \\
113.61 \\
122.72 \\
132.15 \\
141.77 \\
151.49\end{array}$} & \multirow{5}{*}{\begin{tabular}{l|l|}
124.11 \\
132.10 \\
140.50 \\
148.67 \\
156.64 \\
164.54 \\
172.36 \\
179.98
\end{tabular}} & 228.09 & 240.45 \\
\hline & & & & \multicolumn{2}{|c|}{ Series XXIII } \\
\hline & & & & \multirow{3}{*}{$\begin{array}{l}243.23 \\
253.95\end{array}$} & \multirow{3}{*}{$\begin{array}{l}253.23 \\
262.57\end{array}$} \\
\hline & & & & & \\
\hline & & & & & \\
\hline \multicolumn{2}{|c|}{ Series XXVII } & \multicolumn{2}{|c|}{ Series XI } & \multicolumn{2}{|c|}{ Series XXVIII } \\
\hline \multirow{11}{*}{$\begin{array}{l}17.36 \\
18.91 \\
20.70 \\
22.82 \\
25.09 \\
27.64 \\
30.52 \\
33.62 \\
37.11 \\
40.98 \\
45.15 \\
49.69 \\
54.70 \\
60.11\end{array}$} & \multirow{11}{*}{$\begin{array}{l}18.52 \\
21.68 \\
25.24 \\
29.51 \\
34.11 \\
39.18 \\
44.82 \\
50.81 \\
57.19 \\
63.74 \\
70.46 \\
77.43 \\
84.49 \\
91.81\end{array}$} & \multirow{2}{*}{133.74} & \multirow[b]{2}{*}{165.74} & \multirow{3}{*}{$\begin{array}{l}247.56 \\
257.23 \\
\text { Fusion }\end{array}$} & \multirow{3}{*}{$\begin{array}{l}257.09 \\
266.49\end{array}$} \\
\hline & & & & & \\
\hline & & 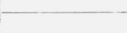 & & & \\
\hline & & \multicolumn{2}{|c|}{ Series XII } & \multicolumn{2}{|c|}{ Series V } \\
\hline & & \multirow{7}{*}{$\begin{array}{l}154.26 \\
164.42 \\
174.36 \\
184.01 \\
193.64 \\
203.39 \\
213.11\end{array}$} & \multirow{7}{*}{$\begin{array}{l}182.05 \\
190.00 \\
197.91 \\
205.31 \\
212.76 \\
220.41 \\
228.13\end{array}$} & \multirow{4}{*}{$\begin{array}{l}251.01 \\
259.77 \\
\text { Fusion }\end{array}$} & \multirow{4}{*}{$\begin{array}{l}259.03 \\
269.61\end{array}$} \\
\hline & & & & & \\
\hline & & & & & \\
\hline & & & & & \\
\hline & & & & \multirow{2}{*}{\multicolumn{2}{|c|}{ Series XIII }} \\
\hline & & & & & \\
\hline & & & & \multirow{2}{*}{$\begin{array}{l}258.37 \\
\text { Fusion }\end{array}$} & \multirow{2}{*}{267.98} \\
\hline \multirow{2}{*}{\multicolumn{2}{|c|}{ Series XXII }} & \multicolumn{2}{|c|}{ Series IX } & & \\
\hline & & & & Serie & \\
\hline \multirow{5}{*}{$\begin{array}{l}56.38 \\
61.96 \\
68.37 \\
75.11 \\
82.05 \\
89.22\end{array}$} & \multirow{5}{*}{$\begin{array}{r}86.74 \\
94.30 \\
102.07 \\
110.01 \\
118.14 \\
125.79\end{array}$} & $\begin{array}{l}208.64 \\
218.93\end{array}$ & $\begin{array}{l}224.50 \\
232.95\end{array}$ & \multirow[b]{2}{*}{260.50} & \\
\hline & & 229.24 & 241.38 & & 270.74 \\
\hline & & 239.56 & 250.36 & & \\
\hline & & 249.59 & 259.17 & Series & \\
\hline & & $\begin{array}{l}259.32 \\
265.80\end{array}$ & $\begin{array}{l}271.65 \\
317.92\end{array}$ & Fusion & \\
\hline
\end{tabular}

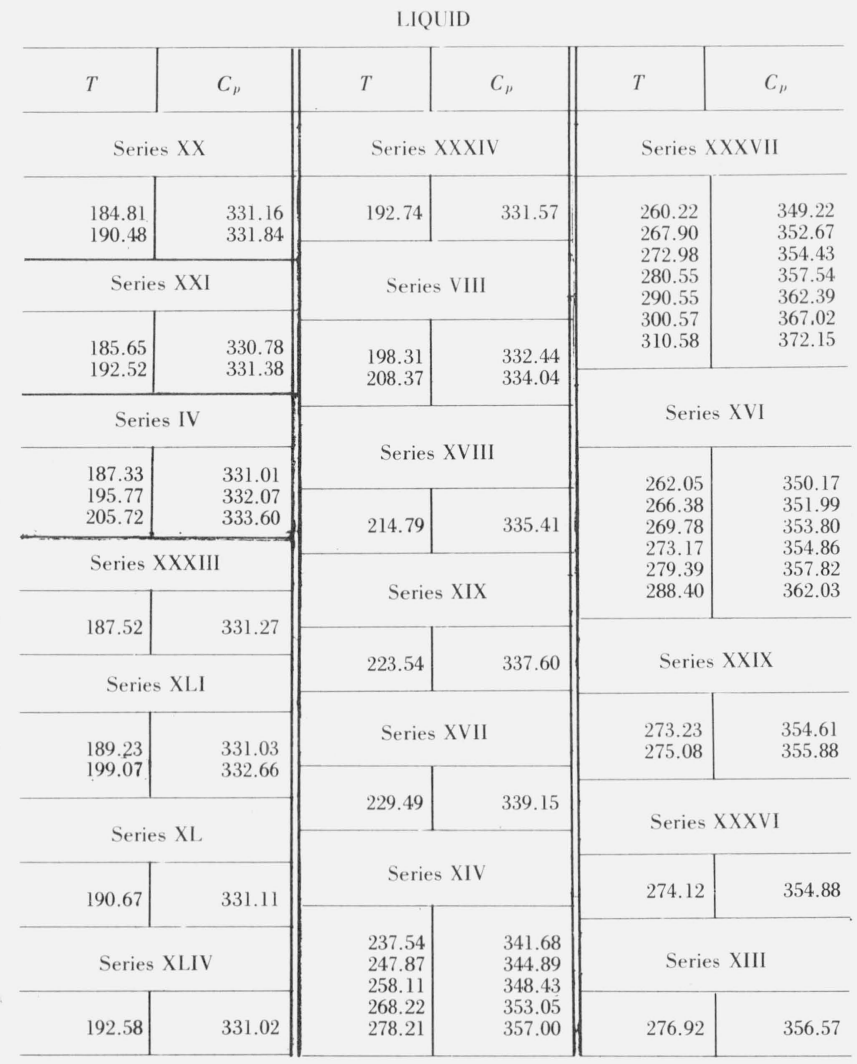

TABLE 2. Heat capacity data for diethyl phthalate-Continued (Units in ${ }^{\circ} \mathrm{K}$. joule and mole)

\begin{tabular}{|c|c|c|c|c|c|}
\hline \multicolumn{6}{|c|}{ LIQUID - Continued } \\
\hline$T$ & $C_{p}$ & $T$ & $C_{p}$ & $T$ & $C_{p}$ \\
\hline \multicolumn{2}{|c|}{ Series VI } & \multicolumn{2}{|c|}{ Series XXXVIII } & \multicolumn{2}{|c|}{ Series VII } \\
\hline $\begin{array}{l}283.41 \\
295.97 \\
306.34 \\
316.44 \\
326.36 \\
336.14\end{array}$ & $\begin{array}{l}359.30 \\
365.24 \\
370.35 \\
375.61 \\
380.14 \\
385.41\end{array}$ & $\begin{array}{l}320.36 \\
330.36 \\
340.27 \\
350.06\end{array}$ & $\begin{array}{l}377.02 \\
382.26 \\
387.30 \\
392.62\end{array}$ & $\begin{array}{l}343.78 \\
353.42\end{array}$ & $\begin{array}{l}389.11 \\
394.56\end{array}$ \\
\hline \multicolumn{6}{|c|}{ QUENCHED C:I.ASS } \\
\hline$T$ & $C_{p}$ & $T$ & $C_{p}$ & $T$ & $C_{p}$ \\
\hline \multicolumn{2}{|c|}{ Series XXV } & \multicolumn{2}{|c|}{ Series 1} & \multicolumn{2}{|c|}{ Series III } \\
\hline \multirow{4}{*}{$\begin{array}{l}11.02 \\
11.62 \\
12.86 \\
14.60 \\
16.53 \\
18.51 \\
20.68 \\
22.92\end{array}$} & \multirow{4}{*}{$\begin{array}{r}8.11 \\
9.37 \\
11.61 \\
14.60 \\
18.22 \\
21.88 \\
26.07 \\
30.46\end{array}$} & $\begin{array}{l}52.25 \\
54.84 \\
60.97\end{array}$ & $\begin{array}{l}80.80 \\
84.40 \\
92.76\end{array}$ & $\begin{array}{l}135.18 \\
145.36 \\
155.10\end{array}$ & $\begin{array}{l}171.25 \\
180.76 \\
190.61\end{array}$ \\
\hline & & \multirow{2}{*}{\multicolumn{2}{|c|}{ Series XXXIX }} & \multicolumn{2}{|c|}{ Series XL } \\
\hline & & & & & \\
\hline & & \multirow{2}{*}{$\begin{array}{l}58.57 \\
64.59\end{array}$} & \multirow{2}{*}{$\begin{array}{l}89.48 \\
97.36\end{array}$} & $\begin{array}{l}150.79 \\
161.24\end{array}$ & $\begin{array}{l}183.04 \\
195.72\end{array}$ \\
\hline \multirow{2}{*}{\multicolumn{2}{|c|}{ Series XXIV }} & & & \multicolumn{2}{|c|}{ Glass Transformation } \\
\hline \multirow{7}{*}{$\begin{array}{l}20.27 \\
21.11 \\
22.91 \\
25.38 \\
28.07 \\
31.03 \\
34.29 \\
37.68 \\
41.44 \\
45.70 \\
50.29 \\
55.28\end{array}$} & & \multirow{2}{*}{\multicolumn{2}{|c|}{ Series II }} & \multicolumn{2}{|c|}{ Series XXI } \\
\hline & \multirow{6}{*}{\begin{tabular}{l|}
25.30 \\
26.80 \\
30.53 \\
35.21 \\
40.38 \\
45.95 \\
52.02 \\
57.94 \\
64.17 \\
71.04 \\
78.06 \\
84.97
\end{tabular}} & & & \multirow{2}{*}{$\begin{array}{l}152.92 \\
163.87 \\
172.03 \\
177.33 \\
181.86\end{array}$} & \multirow{2}{*}{$\begin{array}{l}187.75 \\
199.74 \\
207.85 \\
224.09 \\
315.29\end{array}$} \\
\hline & & \multirow{5}{*}{$\begin{array}{r}67.11 \\
74.39 \\
81.56 \\
88.64 \\
96.05 \\
104.36 \\
113.21 \\
122.47 \\
132.11\end{array}$} & \multirow{5}{*}{$\begin{array}{l}100.70 \\
109.28 \\
117.87 \\
125.81 \\
133.43 \\
141.78 \\
150.61 \\
159.26 \\
168.27\end{array}$} & & \\
\hline & & & & \multicolumn{2}{|c|}{ Series IV } \\
\hline & & & & & \\
\hline & & & & 159.61 & 194.71 \\
\hline & & & & $\begin{array}{l}169.85 \\
179.43\end{array}$ & $\begin{array}{l}207.43 \\
252.67\end{array}$ \\
\hline \multicolumn{6}{|c|}{ ANNEALED GLASS } \\
\hline$T$ & $G_{p}$ & $T$ & $C_{p}$ & $T$ & $C_{p}$ \\
\hline \multicolumn{2}{|c|}{ Series XLII } & \multicolumn{2}{|c|}{ Series XI.III } & \multicolumn{2}{|c|}{ Series XXX } \\
\hline 18.41 & 21.58 & 120.23 & 156.76 & 165.40 & 198.62 \\
\hline 27.97 & 40.07 & 141.12 & 175.90 & Series & \\
\hline $\begin{array}{l}33.76 \\
37.11\end{array}$ & $\begin{array}{l}50.88 \\
56.84\end{array}$ & Series : & & 167.67 & 201.15 \\
\hline $\begin{array}{l}40.88 \\
44.96\end{array}$ & $\begin{array}{l}63.13 \\
69.65\end{array}$ & & & Glass Tran & nation \\
\hline $\begin{array}{l}49.47 \\
54.45\end{array}$ & $\begin{array}{l}76.73 \\
83.64\end{array}$ & $\begin{array}{l}125.07 \\
134.31\end{array}$ & $\begin{array}{l}161.25 \\
169.85\end{array}$ & Serie & \\
\hline 59.88 & 91.09 & 143.63 & 177.99 & & \\
\hline Series $X$ & & $\begin{array}{l}162.64 \\
172.08 \\
178.96 \\
183.08\end{array}$ & $\begin{array}{l}195.77 \\
205.64 \\
269.99 \\
393.95\end{array}$ & $\begin{array}{l}108.84 \\
171.95 \\
175.16 \\
178.45 \\
181.31\end{array}$ & $\begin{array}{l}207.72 \\
215.12 \\
243.96 \\
341.57\end{array}$ \\
\hline 59.17 & 90.43 & Series & & Series & \\
\hline 65.39 & 98.27 & & & & \\
\hline $\begin{array}{l}72.33 \\
79.62\end{array}$ & $\begin{array}{l}106.57 \\
115.28\end{array}$ & 141.27 & 176.06 & 171.22 & 204.81 \\
\hline $\begin{array}{l}87.45 \\
96.35\end{array}$ & $\begin{array}{l}124.16 \\
133.34\end{array}$ & $\begin{array}{l}151.70 \\
161.57\end{array}$ & 185.43 & Series ? & \\
\hline 105.98 & 142.81 & 171.07 & 204.55 & & \\
\hline 115.65 & 152.10 & 180.12 & 316.54 & Glass Tran & nation \\
\hline
\end{tabular}

may be made preferably for the corresponding liquids above the glass transformation range, or if these are not investigated, for the glass samples themselves. The results of several such comparisons will be cited 


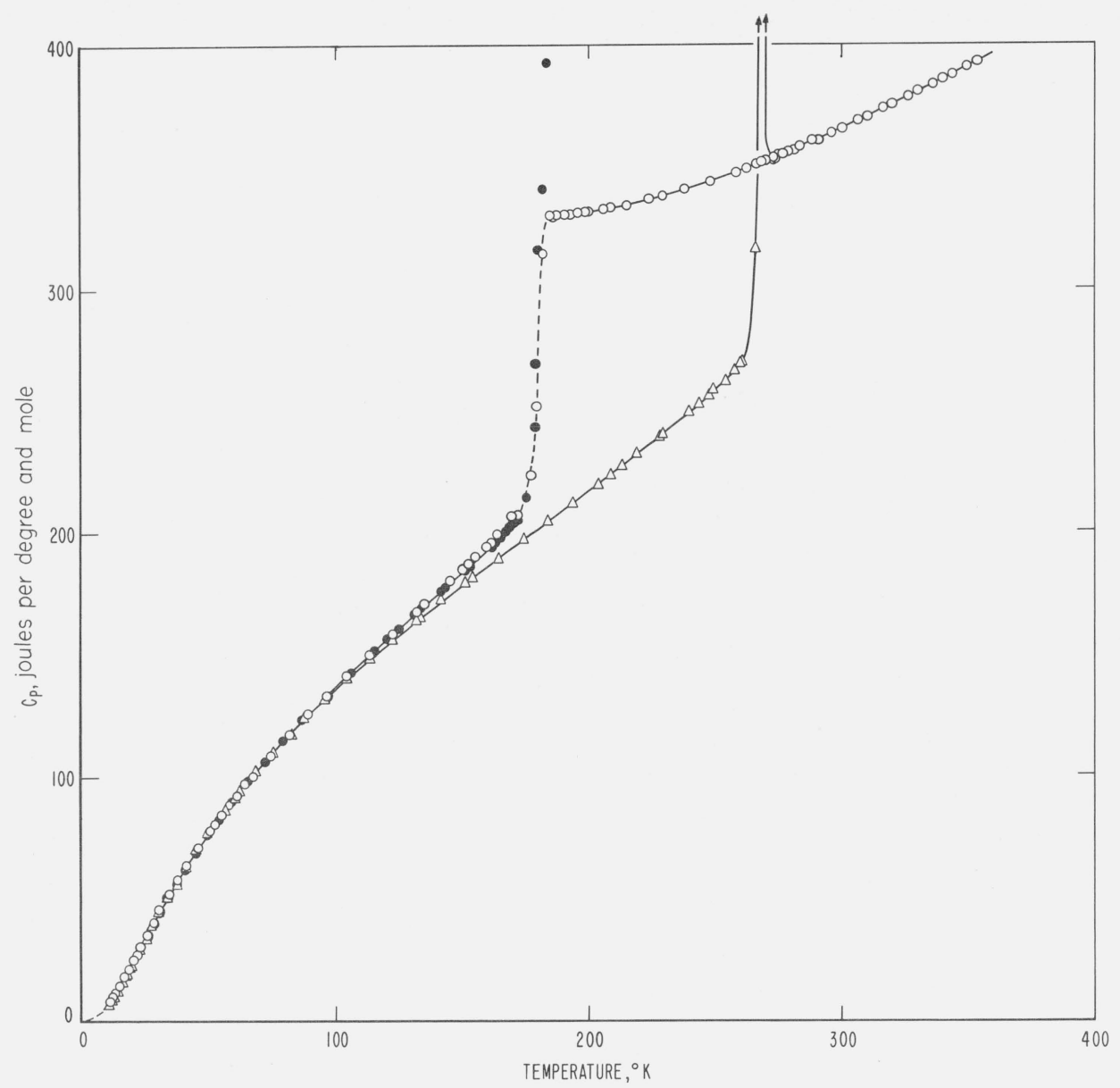

FIGURE 1. Molar heat capacity of diethyl phthalate versus temperature.

Triangles represent crystal, open circles represent liquid and quenched glass, filled circles represent annealed glass.

later in this paper when they become specifically pertinent.

To provide more nearly complete information on the thermal history of the diethyl phthalate investigated, several entries that are not heat capacity data are included in table 2. They indicate only that a fusion or a glass-to-liquid transformation was performed at the indicated point in the course of the measurements. For the glass transformation these indications usually designate heat inputs large enough to encompass most of the transformation process. The results of such determinations are not appropriately represented as heat capacities because the temperature changes concerned are too large to make reliable curvature corrections. Other measurements were made on the glassto-liquid transformation in which the transformation process was encompassed by a number of smaller energy increments. These are represented as heat capacity data in table 2 . Tables 3 and 4 give the results of all the above determinations for enthalpy and entropy changes over temperature intervals encompassing the glass transformation and the fusion processes respectively.
TABLE 3. Glass transformation of diethyl phthalate (Units in ${ }^{\circ} \mathrm{K}$, joule and mole)

\begin{tabular}{|c|c|c|c|c|c|}
\hline Series & No. of runs & $T_{\text {initial }}$ & $T_{\text {final }}$ & $H_{190}^{L}-H_{160}^{6 i}$ & $S_{190}^{L}-S_{160}^{i i}$ \\
\hline \multicolumn{6}{|c|}{ QUENCHED GLASSES } \\
\hline $\begin{array}{l}\text { IV } \\
\text { XXI } \\
\text { XL }\end{array}$ & $\begin{array}{l}3 \\
5 \\
2\end{array}$ & $\begin{array}{l}164.81 \\
158.55 \\
156.05\end{array}$ & $\begin{array}{l}190.90 \\
187.51 \\
186.50\end{array}$ & $\begin{array}{l}7214 . \\
7182 . \\
7141 .\end{array}$ & $\begin{array}{l}40.94 \\
40.71 \\
40.60\end{array}$ \\
\hline \multicolumn{6}{|c|}{ ANNEALED GLASSES } \\
\hline $\begin{array}{l}\text { XX } \\
\text { XXXIII } \\
\text { XXXIV } \\
\text { XLI } \\
\text { XLIV }\end{array}$ & $\begin{array}{l}6 \\
5 \\
1 \\
4 \\
2\end{array}$ & $\begin{array}{l}167.28 \\
157.82 \\
169.95 \\
156.73 \\
162.47\end{array}$ & $\begin{array}{l}186.93 \\
190.06 \\
188.94 \\
193.91 \\
188.92\end{array}$ & $\begin{array}{l}7585 . \\
7791 . \\
7669 . \\
7779 . \\
7641 .\end{array}$ & $\begin{array}{l}43.08 \\
44.11 \\
43.59 \\
44.08 \\
43.36\end{array}$ \\
\hline
\end{tabular}

The results of a fractional melting of diethyl phthalate are given in table 5 . The data at temperatures approaching complete melting were treated by simple melting point depression theory. From the slope of the plot of melting point versus the reciprocal $(1 / F)$ of the fraction of the heat of fusion supplied and the approximate heat of fusion, the mole fraction. $N_{2}$, 
TABLE 4. Fusion of diethyl phthalate (Units in ${ }^{\circ} \mathrm{K}$, joule and mole)

\begin{tabular}{|c|c|c|c|c|c|}
\hline Series & No. of runs & $T_{\text {initial }}$ & $T_{\text {final }}$ & $H_{275}^{L_{275}}-H_{250}^{c}$ & $\Delta H_{f}$ \\
\hline $\begin{array}{l}\text { V } \\
\text { XIII } \\
\text { XXVIII } \\
\text { XXXVI }\end{array}$ & $\begin{array}{l}6 \\
2 \\
2 \\
1 \\
\end{array}$ & $\begin{array}{l}246.56 \\
254.24 \\
251.73 \\
260.16 \\
\end{array}$ & $\begin{array}{l}276.83 \\
274.21 \\
272.42 \\
271.71 \\
\end{array}$ & $\begin{array}{l}25128 . \\
25126 . \\
25134 . \\
25130\end{array}$ & $\begin{array}{l}17982 . \\
17981 . \\
17989 . \\
17985 .\end{array}$ \\
\hline
\end{tabular}

a These represent only the r.m.s. deviations.

of liquid-soluble, solid-insoluble impurity in the sample investigated is determined as 0.0012 . By the device of extrapolating $1 / F$ to zero the melting point of the pure substance is determined as $269.92 \pm 0.02{ }^{\circ} \mathrm{K}$.

The heat of fusion is obtained from the enthalpy change through the melting region by subtracting the heat capacity integral over this region. This requires the correction of some observed crystal heat capacities for the heat absorbed by fusion (premelting) at the lower temperatures in the melting range. Attempts to do this using simple melting point depression theory over the entire melting range with the above result (and other trial values) for $N_{2}$ gave unacceptable results, suggesting that the simple theory is not adequate

TABLE 5. Fractional melting of diethyl phthalate

\begin{tabular}{l|r}
\hline \multicolumn{1}{c|}{$T^{\circ} \mathrm{K}$} & $\frac{1}{F}$ \\
\hline & \\
269.386 & 13.393 \\
269.810 & 2.652 \\
269.872 & 1.276 \\
Triple point of sample & 1.000 \\
269.88 & 0.000 \\
Triple point of pure diethyl phthalate & \\
269.92 & \\
Mole fraction of impurities $=0.0012$ & \\
\hline
\end{tabular}

over the entire range. The base line for heat capacity in the premelting region was therefore established arbitrarily. The resulting value for the heat of fusion of the calorimetric sample at the above temperature is $17,984 \pm 3$ joules per mole. In view of the uncertainties involved the accuracy of this value is estimated as \pm 0.1 percent of the value.

If we assume that the molecular weight of the impurity in the sample is the same as that of diethyl phthalate, the above value is corrected to 18,006 joules per mole as the heat of fusion of pure diethyl phthalate at its melting point. Since the molecular weight of the impurity is unknown, we arbitrarily assign to this correction an uncertainty equal to the value of the correction ( 22 joules per mole). This corresponds to assuming that the molecular weight of the impurity lies between zero and twice the value of that of diethyl phthalate.

With the intention of obtaining quantitative information about enthalpy changes, the behavior of the calorimeter was followed during several instances of crystallization processes, namely at the end of run series IV, VIII, XVIII, and XLI. The rate of spontaneous temperature rise increases progressively after the commencement of crystallization around $210-220{ }^{\circ} \mathrm{K}$, and then remains at a maximum rate of 4 to $5{ }^{\circ} \mathrm{K}$ per minute from $235{ }^{\circ} \mathrm{K}$ until a final temperature of 260 to $265^{\circ} \mathrm{K}$. As a result of failure of the adiabatic shield to follow closely to the temperature of the calorimeter during the crest of crystallization process, a certain amount of heat released by the sample was lost to the shield. Depending upon the different degrees of deviation from adiabaticity for the individual cases, the values of heat of fusion calculated from crystallization processes vary from 0.15 to 0.75 percent higher than that from actual fusion processes.

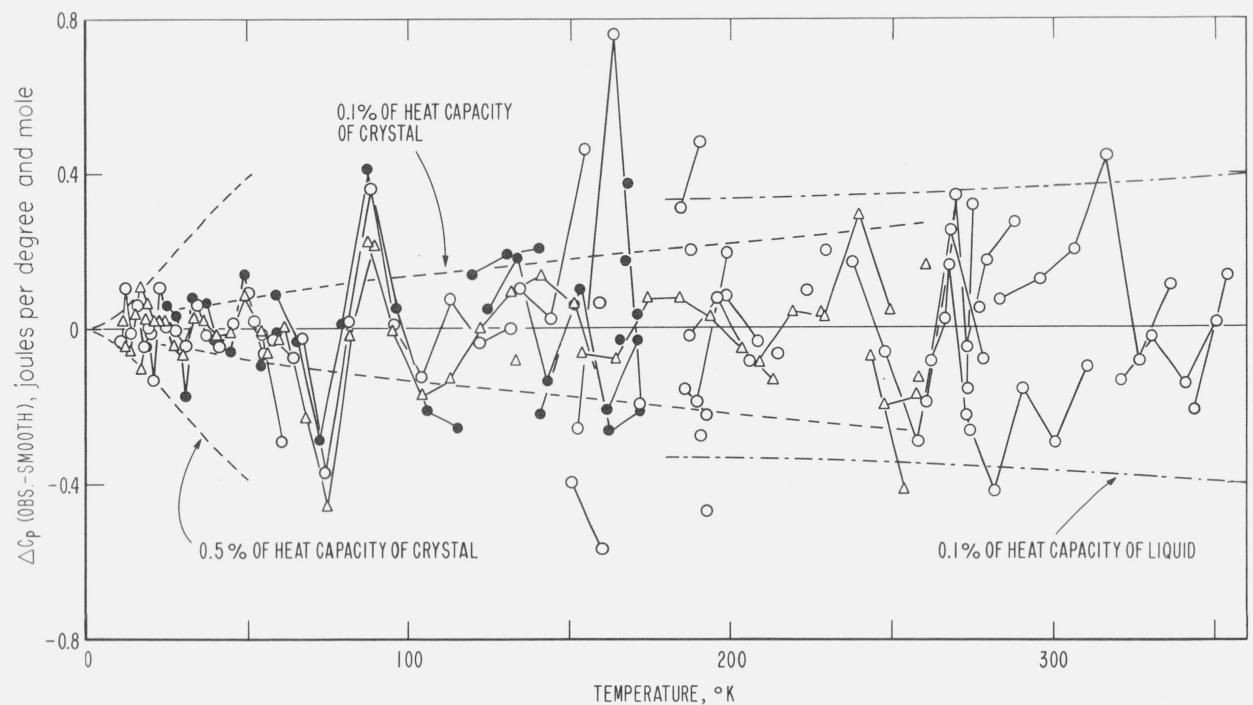

FIGURE 2. Deviation of individual heat capacity points from smoothed values for diethyl phthalate. Triangles represent crystal, open circles represent liquid and quenched glass, filled circles represent annealed glass. 


\section{Analysis of Data}

\subsection{Representation and Precision of Heat Capacities}

Figure 2 shows the deviations of the individual heat capacity points from the smooth values for the physical forms concerned. The smoothed values were obtained by fitting the individual values with three to six degree polynomials in temperature using an IBM 7094 digital computer and Fortran programming. The crystal data were fitted in three segments and the data for the glasses in two segments. Adjacent segments overlapped by $10^{\circ}$ to $30^{\circ}$ in temperature. Individual data points for the crystal near its melting point were omitted from the curve fitting if their final temperature was above $264^{\circ} \mathrm{K}$ because some of the energy represented by them may have been latent heat of fusion rather than thermal energy. Individual data points for the glasses near the glass transformation temperatures were omitted from the curve fitting if their final temperature was above $175{ }^{\circ} \mathrm{K}$ for the quenched glass or above $180^{\circ} \mathrm{K}$ for the annealed glass because of uncertainty in the correction for configurational change during individual determinations.

The root mean square percentage deviations of the heat capacities from the polynomials at temperatures above $25^{\circ} \mathrm{K}$ are less than 0.1 percent (usually about $0.07 \%$ ). As temperatures decrease below $25 \mathrm{~K}$, the root mean square deviation increases, reaching about 0.5 percent around $10{ }^{\circ} \mathrm{K}$.

The smoothed heat capacity values are listed in table 6 . These values together with the data from tables 3 and 4 result in the values listed in table 6 for the usually stated thermodynamic functions for diethyl phthalate crystal, liquid, and glass. For the crystal and for the liquid above the melting temperature these functions were calculated by integrating the appropriate integrand from absolute zero temperature to the temperature concerned. For the supercooled liquid and the glass, the calculations proceeded from the values (obtained as above) for the liquid at the melting temperature. From these were subtracted the integrals of the appropriate integrands for the glass and the supercooled liquid from the temperature concerned to the melting temperature.

The integrals between absolute zero temperature and the lowest temperature of measurement (around $10^{\circ} \mathrm{K}$ ) were obtained by extrapolation assuming heat capacity proportional to $T^{3}$ at these temperatures. The resulting values for the integrals differ from values for the same integrals obtained by graphical extrapolation by less than the uncertainty of the experimentally determined integrals between 10 and $35^{\circ} \mathrm{K}$.

The minimum and maximum in the heat capacity deviations between 70 and $100{ }^{\circ} \mathrm{K}$ are attributed to a peculiarity in the temperature scale used. This peculiarity has been discussed previously by Furukawa and Reilly [3] and by Roder [4].

Figure 2 also suggests a small peak within the 0.1 percent uncertainty limits around $270{ }^{\circ} \mathrm{K}$. This may be associated with some suspected minute aqueous inclusion in the empty calorimeter which may have an irreproducible freezing behavior. This matter is currently under further investigation.

\subsection{Glass Versus Crystal}

The relative behavior of heat capacity as a function of temperature for the crystal and the quenched and annealed glasses can be discussed conveniently with reference to figure 3 . This shows plots as functions of temperature of the differences between the heat capacities of the crystal and of the two different glasses. The immediately noticeable general feature is that, contrary to widely held belief [5], the heat capacity of the glass differs from that of the

TABLE 6. Thermodynamic functions of diethyl phthalate (Units in ${ }^{\circ} \mathrm{K}$, joule and mole. Reference state $=$ crystal)

CRYSTAL

\begin{tabular}{|c|c|c|c|c|c|c|}
\hline$T$ & $C_{p}$ & $H-H_{0}^{\circ}$ & $\left(H-H_{0}^{\circ}\right) / T$ & $S$ & $-\left(G-H_{0}^{\circ}\right) / T$ & $-\left(G-H_{0}^{\circ}\right)$ \\
\hline 10 & 5.91 & 14.8 & 1.48 & 1.97 & 0.49 & 4.9 \\
\hline 15 & 14.23 & 64.4 & 4.29 & 5.88 & 1.59 & 23.8 \\
\hline 20 & 23.84 & 159.2 & 7.96 & 11.27 & 3.31 & 66 \\
\hline 25 & 33.91 & 303.5 & 12.14 & 17.67 & 5.53 & 138.1 \\
\hline 30 & 43.86 & 498.1 & 16.60 & 24.73 & 8.13 & 243.9 \\
\hline 35 & 53.32 & 741.3 & 21.18 & 32.21 & 11.03 & 386.2 \\
\hline 40 & 62.12 & 1030.2 & 25.75 & 39.91 & 14.16 & 566 \\
\hline 45 & 70.27 & 1361.4 & 30.25 & 47.71 & 17.45 & 785.4 \\
\hline 50 & 77.81 & 1731.9 & 34.64 & 55.51 & 20.87 & 1043.5 \\
\hline 60 & 91.64 & 2580.1 & 43.00 & 70.93 & 27.93 & 1675.9 \\
\hline 70 & 104.25 & 3560.5 & 50.86 & 86.02 & 35.16 & 2461.0 \\
\hline 80 & 115.80 & 4661.6 & 58.27 & 100.71 & 42.44 & 3395.0 \\
\hline 90 & 126.43 & 5873.4 & 65.26 & 114.97 & 49.71 & 4473 \\
\hline 100 & 136.31 & 7187.7 & 71.88 & 128.81 & 56.93 & 5693.0 \\
\hline 110 & 145.58 & 8597.6 & 78.16 & 142.24 & 64.08 & 7048.5 \\
\hline 120 & 154.35 & 10098. & 84.15 & 155.28 & 71.14 & 8536.5 \\
\hline 130 & 162.74 & 11683. & 89.87 & 167.97 & 78.10 & 10153. \\
\hline 140 & 170.86 & 13352. & 95.37 & 180.33 & 84.96 & 11895. \\
\hline 150 & 178.79 & 15100. & 100.67 & 192.39 & 91.72 & 13759. \\
\hline 160 & 186.61 & 16927. & 105.79 & 204.18 & 98.39 & 15742. \\
\hline 170 & 194.38 & 18832. & 110.78 & 215.73 & 104.95 & 17841. \\
\hline 180 & 202.14 & 20815. & 115.64 & 227.06 & 111.42 & 20056. \\
\hline 190 & 209.94 & 22875 . & 120.39 & 238.19 & 117.80 & 22382. \\
\hline 200 & 217.75 & 25014. & 125.07 & 249.16 & 124.09 & 24819. \\
\hline 210 & 225.57 & 27230 . & 129.66 & 259.97 & 130.31 & 27365 . \\
\hline 220 & 233.80 & 29526. & 134.21 & 270.66 & 136.44 & 30018. \\
\hline 230 & 242.16 & 31906. & 138.72 & 281.23 & 142.51 & 32777. \\
\hline 240 & 250.52 & 34369. & 143.21 & 291.71 & 148.51 & 35642 . \\
\hline 250 & 259.31 & 36918. & 147.67 & 302.12 & 154.45 & 38612. \\
\hline 260 & 269.93 & 39561. & 152.16 & 312.48 & 160.32 & 41684. \\
\hline
\end{tabular}

LIQUID

\begin{tabular}{l|r|r|r|r|r|l}
\hline & & & & & & \\
190 & 331.31 & 33051. & 173.95 & 270.07 & 96.11 & 18261. \\
200 & 332.59 & 36370. & 181.85 & 287.09 & 105.24 & 21048. \\
220 & 334.37 & 39705. & 189.07 & 303.36 & 114.29 & 24000. \\
230 & 336.60 & 43059. & 195.72 & 318.96 & 123.24 & 27113. \\
& 339.25 & 46438. & 201.90 & 333.98 & 132.08 & 30378. \\
240 & 342.30 & 49845. & 207.69 & 348.48 & 140.79 & 33790. \\
250 & 345.71 & 53285. & 213.14 & 362.52 & 149.38 & 37346. \\
270 & 349.44 & 56761. & 218.31 & 376.15 & 157.84 & 41040. \\
280 & 353.48 & 60275. & 223.24 & 389.42 & 166.18 & 44868. \\
& 357.78 & 63831. & 227.97 & 402.35 & 174.38 & 48827. \\
390 & 362.31 & 67431. & 232.52 & 414.98 & 182.46 & 52914. \\
310 & 367.04 & 71078. & 236.93 & 427.35 & 190.42 & 57125. \\
320 & 371.94 & 74773. & 241.20 & 439.46 & 198.26 & 61460. \\
330 & 382.97 & 78517. & 245.37 & 451.35 & 205.98 & 65914. \\
& & 82312. & 249.43 & 463.03 & 213.59 & 70486. \\
340 & 387.33 & 86160. & 253.41 & 474.51 & 221.10 & 75174. \\
360 & 392.58 & 90059. & 257.31 & 485.81 & 228.50 & 79976. \\
273.15 & 397.84 & 94011. & 261.14 & 496.95 & 235.80 & 84890. \\
298.15 & 354.80 & 61391. & 224.75 & 393.53 & 168.78 & 46101. \\
& 366.15 & 70340. & 236.12 & 425.08 & 188.96 & 56337. \\
\hline
\end{tabular}


TABLE 6. Thermodvnamic functions of diethyl phthalate-Continued

(Units in ${ }^{\circ} \mathrm{K}$. joule and mole. Reference state $=$ crystal)

QUENCHED GLASS

\begin{tabular}{l|r|r|r|r|r|r}
\hline & & & & \\
& \multicolumn{1}{c|}{$C_{p}$} & $H-H_{0}^{\circ}$ & $\left(H-H_{0}^{\circ}\right) / T$ & $S$ & $-\left(G-H_{0}^{\circ}\right) / T$ & $-\left(G-H_{0}^{\circ}\right)$ \\
\hline 10 & & & & & & \\
15 & 6.44 & 8737. & 873.69 & 24.57 & -849.12 & -8491. \\
20 & 15.39 & 8791. & 586.08 & 28.85 & -557.23 & -8358. \\
25 & 24.80 & 8892. & 444.58 & 34.56 & -410.02 & -8200. \\
30 & 34.43 & 9040. & 361.58 & 41.13 & -320.46 & -8011. \\
& 43.99 & 9236. & 307.86 & 48.25 & -259.61 & -7788. \\
35 & 53.23 & 9479. & 270.83 & 55.73 & -215.09 & -7528. \\
40 & 61.95 & 9767. & 244.18 & 63.42 & -180.76 & -7231. \\
45 & 70.03 & 10097. & 224.39 & 71.19 & -153.20 & -6894. \\
50 & 77.47 & 10467. & 209.33 & 78.96 & -130.37 & -6519. \\
60 & 91.44 & 11312. & 188.53 & 94.33 & -94.20 & -5652. \\
70 & 104.29 & 12291. & 175.59 & 109.41 & -66.19 & -4633. \\
80 & 116.13 & 13394. & 167.43 & 124.11 & -43.31 & -3465. \\
90 & 127.14 & 14611. & 162.35 & 138.44 & -23.91 & -2152. \\
100 & 137.49 & 15935. & 159.35 & 152.37 & -6.98 & -698. \\
110 & 147.34 & 17359. & 157.81 & 165.94 & 8.13 & 894. \\
& & & & & & \\
120 & 156.86 & 18880. & 157.34 & 179.17 & 21.83 & 2620. \\
130 & 166.24 & 20496. & 157.66 & 192.10 & 34.44 & 4477. \\
140 & 175.62 & 22205. & 158.61 & 204.76 & 46.15 & 6461. \\
150 & 185.20 & 24009. & 160.06 & 217.20 & 57.14 & 8571. \\
160 & 195.13 & 25910. & 161.94 & 229.47 & 67.53 & 10804. \\
170 & 205.82 & 27915. & 164.21 & 241.62 & 77.41 & 13160. \\
\hline & & & & & \\
\hline
\end{tabular}

ANNEALED GLASS

\begin{tabular}{l|r|r|r|r|r|r}
\hline 15 & 15.05 & 8205. & 547.03 & 26.05 & -520.98 & -7815. \\
20 & 24.66 & 8305. & 415.23 & 31.69 & -383.54 & -7671. \\
25 & 34.37 & 8452. & 338.09 & 38.23 & -299.85 & -7496. \\
30 & 43.91 & 8648. & 288.27 & 45.35 & -242.92 & -7288. \\
35 & 53.07 & 8891. & 254.02 & 52.81 & -201.21 & -7042. \\
& & & & & & \\
40 & 61.72 & 9178. & 229.45 & 60.47 & -168.98 & -6759. \\
45 & 69.81 & 9507. & 211.26 & 68.21 & -143.05 & -6437. \\
50 & 77.36 & 9875. & 197.50 & 75.96 & -121.54 & -6077. \\
60 & 91.23 & 10719. & 178.65 & 91.31 & -87.34 & -5240. \\
70 & 104.00 & 11696. & 167.08 & 106.34 & -60.74 & -4252. \\
& & & & & & \\
80 & 115.80 & 12796. & 159.95 & 121.01 & -38.94 & -3115. \\
90 & 126.79 & 14009. & 155.66 & 135.29 & -20.37 & -1833. \\
100 & 137.11 & 15329. & 153.29 & 149.19 & -4.10 & -410. \\
110 & 146.92 & 16750. & 152.27 & 162.72 & 10.45 & 1149. \\
120 & 156.37 & 18266. & 152.22 & 175.91 & 23.69 & 2843. \\
130 & 165.60 & 19876. & 152.90 & 188.79 & 35.90 & 4667. \\
140 & 174.78 & 21578. & 154.13 & 201.40 & 47.27 & 6618. \\
150 & 184.03 & 23372. & 155.82 & 213.77 & 57.96 & 8694. \\
160 & 193.53 & 25260. & 157.87 & 225.95 & 68.08 & 10893. \\
170 & 203.42 & 27245. & 160.26 & 237.98 & 77.72 & 13212. \\
\hline
\end{tabular}

crystal in a more complicated way than by a slight increase due to a lowering of all vibrational force constants resulting from the greater specific volume of the glass. The deviation of the heat capacity of the glass from that of the crystal is not uniform over their entire common temperature range. It is qualitatively different in different segments of the temperature range.

The commonly expected relationship of glass heat capacity exceeding crystal heat capacity does apply for diethyl phthalate at temperatures immediately below $T_{g}$, even at temperatures low enough (say below $170^{\circ} \mathrm{K}$ ) so that the molecular configurations in the glass may be presumed to remain fixed so that no glass transformation effects occur. However, the increment decreases rapidly with decreasing temperature (even in a relative sense) until at temperatures somewhat below $100{ }^{\circ} \mathrm{K}$ the heat capacity of the glass falls below that of the crystal.

In the temperature range about from 30 to $75{ }^{\circ} \mathrm{K}$ the heat capacities of both diethyl phthalate glasses investigated are lower than that of the crystal. The values for the annealed glass are as much as 0.6 percent below the values for the crystal, and the maximum difference for the quenched glass is about 0.3 percent. Thus the difference is definitely greater than the experimental uncertainty of the values, though of the same order of magnitude.

For several other substances the heat capacity of the glass has also been reported as lower than that of the crystal over some temperature range [6-10]. These are summarized in table 7.

However, reliable data exist for a number of other substances for which it is clear that the heat capacities of the glass are unequivocally higher than those for the crystal at all temperatures between the lowest temperature of measurement (which are near or below $10{ }^{\circ} \mathrm{K}$ in many cases) and the glass transformation temperature. It follows that no universally applicable conclusion can be made as to the

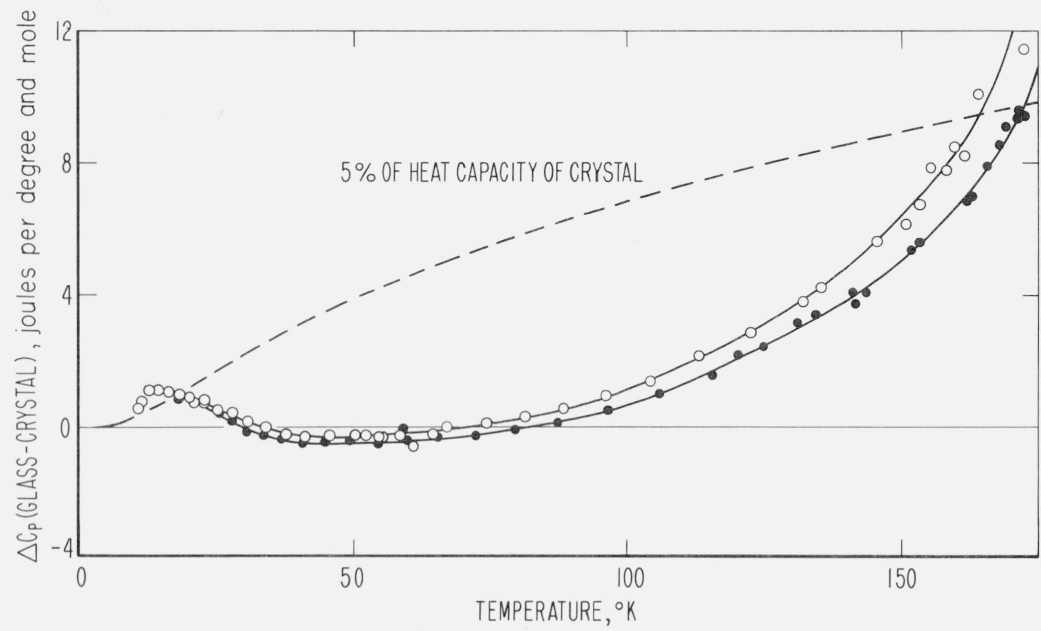

FIGURE 3. Difference between heat capacities of diethyl phthalate glass and crystal. Open circles represent quenched glass, filled circles represent annealed glass. 
TABLE 7. Glasses having lower heat capacities than their crystals

\begin{tabular}{|c|c|c|c|c|}
\hline Substance & Reference & $\begin{array}{c}\text { Temperature } \\
\text { range }{ }^{\circ} K\end{array}$ & $\begin{array}{l}\text { Maximum } \\
\text { difference }\end{array}$ & $\begin{array}{l}\text { Experimental } \\
\text { uncertainty }\end{array}$ \\
\hline $\begin{array}{l}\text { Diethyl Phthalate } \\
\text { d,1- Lactic Acid } \\
\text { Selenium } \\
\text { Sodium Tetraborate } \\
\text { Boron Trioxide } \\
\text { Silicon Dioxide } \\
\text { Pyroxane } \\
\text { Anorthite }\end{array}$ & $\begin{array}{l}\text { This work } \\
{[6]} \\
{[7]} \\
{[8]} \\
{[8]} \\
{[9]} \\
{[10]} \\
{[10]}\end{array}$ & $\begin{array}{l}30-75 \\
<90-170 \\
\sim 100-\sim 200 \\
35->350 \\
300-(?) \\
\sim 200->300 \\
300-800 \\
300-400\end{array}$ & $\begin{array}{ll}\% & \\
& 0.6 \\
3 \\
1 \\
3 \\
\\
1 \\
0.3 \\
0.9\end{array}$ & $\begin{array}{ll}\% & \\
& 0.1 \\
& 0.3 \\
1 \\
\\
0.1 \\
\\
\\
0.1 \\
0.3 \\
0.3\end{array}$ \\
\hline
\end{tabular}

relative magnitude of the heat capacities of the glassy and the crystalline forms of a substance. This fact is in no way disconcerting. It simply indicates that the molecular motions in the glass and in the crystal differ in a more complicated way than corresponds to any universal type shift in their heat capacity function. It appears inappropriate to view the equations of molecular motion for a glass as only minor variations of those of the crystal of the same substance. What appears necessary eventually is to investigate the equations of molecular motion of glasses in their own right.

\subsection{Low Temperature Heat Capacity of Glass}

At the lowest temperatures of measurement, just above $10^{\circ} \mathrm{K}$, the heat capacity values for diethyl phthalate glass rise as much as 8 percent higher than those for the crystal. This feature is reminiscent of, though possibly distinct from, observations which have been made on other glasses in recent years. These observations all involve a glass at sufficiently low temperatures having higher heat capacity values than would be expected according to some kind of conventional considerations usually based at least implicitly on concepts strictly applicable to crystals.

For vitreous silica the ratio of measured heat capacity to temperature cubed $\left(C / T^{3}\right)$, extrapolated to absolute zero temperature, is about twice the value calculated from measured elastic constants [11]. Flubacher, Leadbetter, Morrison, and Stoicheff [12] as well as Rosenstock [13] have discussed proposed explanations of this discrepancy in terms of optical modes of molecular motion having unusually low frequencies. The former authors [12] have also reported contributions corresponding to such frequencies (on the order of $1-100 \mathrm{~cm}^{-1}$ ) in the Raman and Brillouin spectra of vitreous silica.

It has been suggested to apply the same proposition to vitreous glycerol, for which the plot of $C / T^{3}$ versus $T^{2}$ shows a minimum slightly above $2{ }^{\circ} \mathrm{K}$ and increases with further decreasing temperature down to the lowest temperature of measurement (around $1.5^{\circ} \mathrm{K}$ ) [14]. Similar minima have been observed for several alkali-silicate glasses around 6 to $7{ }^{\circ} \mathrm{K}$, with the measurements extending down to slightly above $5{ }^{\circ} \mathrm{K}[15]$. Such minima are, however, a distinctly different type of observation from that mentioned above for vitreous silica, though the same type of explanation can be applied to both. The explanation of the minima requires a much more drastic effect than does that of the $C / T^{3}$ discrepancy. The minima are also more susceptible to scepticism about experimental finality than is the $C / T^{3}$ discrepancy, since the minima could result spuriously from relatively simple distortions of the temperature scale, whereas the $C / T^{3}$ discrepancy could not. Very careful measurements on vitreous silica [12] reveal no suggestion of any minimum in the $C / T^{3}$ versus $T^{2}$ plot in the low temperature region extending down to slightly below $2.5^{\circ} \mathrm{K}$.

Simon and Lange [16] reported that the heat capacity of amorphous glycerol rises markedly above that of the crystal as temperature decreases below about $70{ }^{\circ} \mathrm{K}$, becoming about 80 percent higher at $10{ }^{\circ} \mathrm{K}$.

For vitreous polyethylene the limit at absolute zero temperature of calorimetric values for $C / T^{3}$ is about three times the value for the crystal [17]. This comparison is strictly different than that between the calorimetric and the mechanical values for the $C / T^{3}$ limit. However, in a rough way it is suggestive of the same kind of discrepancy, if one assumes that the mechanical value for the glass is not too far above the calorimetric value for the crystal. This is the case for silica, for instance; the mechanical value for the glass is less than twice the calorimetric value for the crystalline form quartz [18]. The same type of differences between calorimetric and mechanical results have been claimed for amorphous polystyrene and polymethyl methacrylate on the basis of sound velocity results extrapolated from $140{ }^{\circ} \mathrm{K}$ to absolute zero temperature [19].

The heat capacity values reported in the present paper for diethyl phthalate are at too high temperatures (above $10^{\circ} \mathrm{K}$ ) to extrapolate to a limiting value of $C / T^{3}$. The effects of the classical equipartition limit are still apparent. The relatively high heat capacity values for the glass between 10 and $30{ }^{\circ} \mathrm{K}$ are however still amenable to the same type of explanation as discussed in the preceeding paragraphs; namely, unusually low frequencies of molecular motion. In this case however, the possibility of low acoustical frequencies is not eliminated. To determine whether any unusually low frequencies present were acoustical would require heat capacity measurements at still lower temperatures (say about $4{ }^{\circ} \mathrm{K}$, or preferably around $2^{\circ} \mathrm{K}$ ), as well as low temperature acoustical measurements on vitreous diethyl phthalate.

The idea of the general existence of unusually low frequencies of optical modes of molecular motion in glasses is one which may be related to their amorphous nature. Rosenstock [13] discusses them in terms of physical regions of "localized" low-frequency molecular oscillations. Anderson [11] argues that in vitreous silica these are more likely to be associated with small intermolecular force constants than with large molecular masses oscillating as rigid units.

Such regions have also been mentioned as pussibly instrumental in several types of physical phenomena other than heat capacities. Such regions might be 
identified with the "defects" of the defect-diffusion model discussed by Glarum [20] and by Hunt and Powles [21] to explain dielectric relaxation in liquid and vitreous isobutyl bromide, and nuclear spin relaxation, dielectric relaxation and indirectly ultrasonic absorption in liquid and vitreous glycerol. At relatively low temperatures, near and below the glass transformation, Hunt and Powles find the defect-diffusion mechanism in itself sufficient to reproduce observed molecular relaxation phenomena, though at higher temperatures an additional mechanism is necessary both in Hunt and Powles' and in Glarum's treatments. Klemens' [22] treatment of the temperature dependence of low temperature thermal conductivity of vitreous silica can be interpreted in terms of such regions, and he has proposed an explanation [23] of the temperature dependence of the spin-lattice relaxation of vitreous silica in terms of defects with low frequency mechanical resonances (around $20 \mathrm{~cm}^{-1}$ ).

In view of the repeated emergence of this idea in connection with diverse physical properties, definitive evidence about its generality is especially important. This requires further direct structural investigations.

\subsection{Comparison of Annealed and Quenched Glasses}

According to current understanding of the glass transformation process, the principal difference in thermal properties between a quenched and an annealed glass arises because the annealed loses more enthalpy on cooling through the glass transformation region than does the quenched. This is illustrated in figure 4, which shows the enthalpy increment below the equilibrium supercooled liquid at $190{ }^{\circ} \mathrm{K}$ for both the quenched and the annealed glasses. There is a corresponding difference in the entropies. The curves in figure 4 represent respectively the most drastically quenched glass and the most thoroughly annealed glass investigated. For these glasses at $160{ }^{\circ} \mathrm{K}$, just below the glass transformation region, the entropy of the quenched glass is 3.5 joule per degree and mole higher than that of the annealed, which is in turn 22 joule per degree and mole higher than that of the crystal. At absolute zero temperature the entropy of the quenched glass is 2.9 joule per degree and mole higher than that of the annealed, which is in turn 20 joule per degree and mole higher than that of the crystal.

The residual entropy at absolute zero temperature is therefore 20 joule per degree and mole for the annealed glass and 23 joule per degree and mole for the quenched glass. Certain implications of the residual entropies of glasses were discussed in more detail in reference [24].

The glass transformation temperatures specified for the annealed and the quenched glasses respectively by the intersections of the (extrapolated) enthalpy versus temperature plots for the equilibrium supercooled liquid and the configurationally fixed glasses are $176.5^{\circ} \mathrm{K}$ and $180.8^{\circ} \mathrm{K}$.

The decrease in the entropy difference between the two glasses as temperature decreases from just below

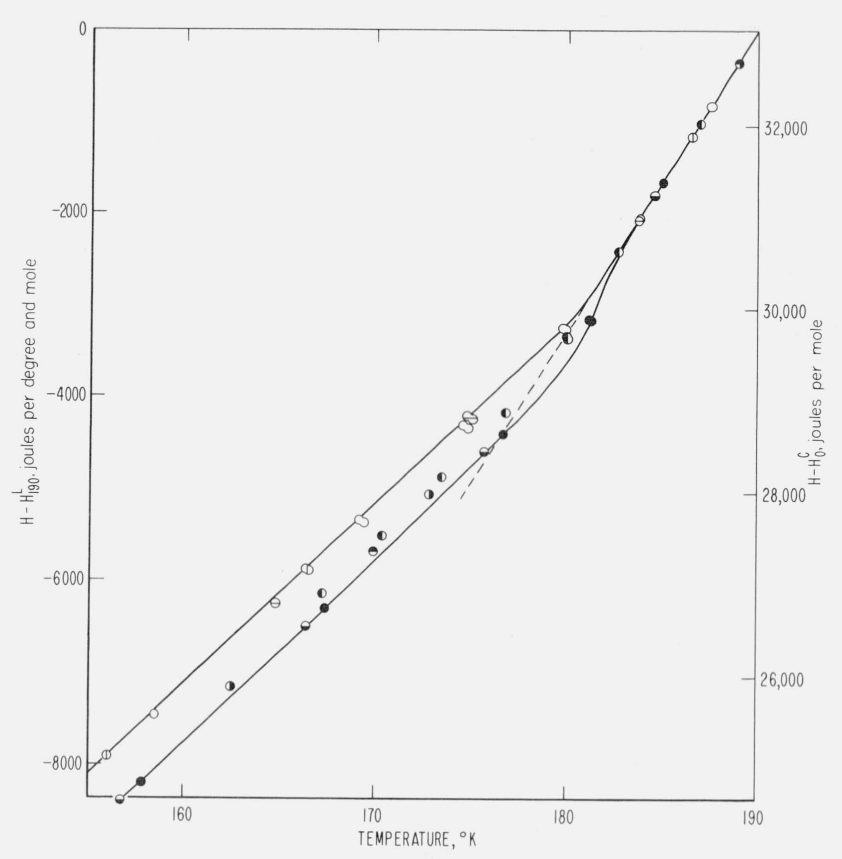

FIGURE 4. Enthalpy plot for amorphous diethyl phthalate near glass transformation temperature region.

Open and barred circles represent quenched glasses. Shaded circles represent annealed glasses.

the glass transformation region to absolute zero is due to the difference in the heat capacities of the two glasses. At the precision of the present measurements, this difference is observable, as illustrated in figure 3 . Even well below the glass transformation region the heat capacity of the annealed glass is lower than that of the quenched by more than the uncertainty of the measurements. As low as $30^{\circ} \mathrm{K}$ the annealed is 0.5 percent lower than the quenched, with an uncertainty of measurement less than 0.1 percent. It may be noted however that although the different quenched glasses respectively, as well as the different annealed glasses, show differences in the enthalpy change through the glass transformation, no heat capacity differences beyond the limits of uncertainty of the present measurements are detectable between any of the quenched glasses or between any of the annealed glasses investigated.

The possibility of this heat capacity difference arising spuriously from partial crystallization of the annealed glass can be eliminated by the fact that no difference is observed between the heat capacities for the equilibrium supercooled liquids resulting from heating the annealed and the quenched glasses respectively through the glass transformation region, as anticipated in subsection 2.3. At $190{ }^{\circ} \mathrm{K}$ the heat capacity of the equilibrium supercooled liquid decreases from about 335 to 210 joule per degree and mole on crystallization. At $160{ }^{\circ} \mathrm{K}$ the heat capacity of the quenched glass decreases from about 195 to 186 joule per degree and mole on crystallization. Therefore, any relative difference between the heat capacities of 
the two glasses due to partial crystallization of one of them would be magnified by a factor near ten in compering the corresponding equilibrium supercooled liquids. Comparison of the results for heat capacity Series IX, XX, and XXXIX with those for Series XIX, XXXII, XXXIII, XL, and XLIII shows that the heat capacities are the same within the calorimetric limits of uncertainty for the equilibrium supercooled liquids corresponding to the quenched and the annealed glasses respectively. Therefore the observed difference between the heat capacities of the two glasses has no measurable contribution due to partial crystallization of either of them.

The uniformly lower heat capacities of the annealed glass, as compared with the quenched, is consistent with the proposition that the intermolecular force constants in the annealed glass are greater as indicated by the decrease in specific volume generally associated with annealing.

The fact that the difference between the entropies of the annealed and the quenched glasses at temperatures just below the glass transformation region varies only slightly from the difference between their residual entropies at absolute zero temperature is consistent with approximating the (fixed) configurational entropy of a glass by its residual entropy at absolute zero temperature. This approximation and the consequences of its application are discussed in more detail in reference [24].

Reference [24] also dwells at some length on the fact that an annealed glass maintains its fixed molecular configurations at temperatures much closer to the glass transformation proper than does quenched glass. A clear concrete demonstration of this fact for diethyl phthalate is provided in figure 5 , which is presented specifically for this purpose. It shows the (configurational) drifts of calorimeter temperature between individual calorimetric energy inputs for

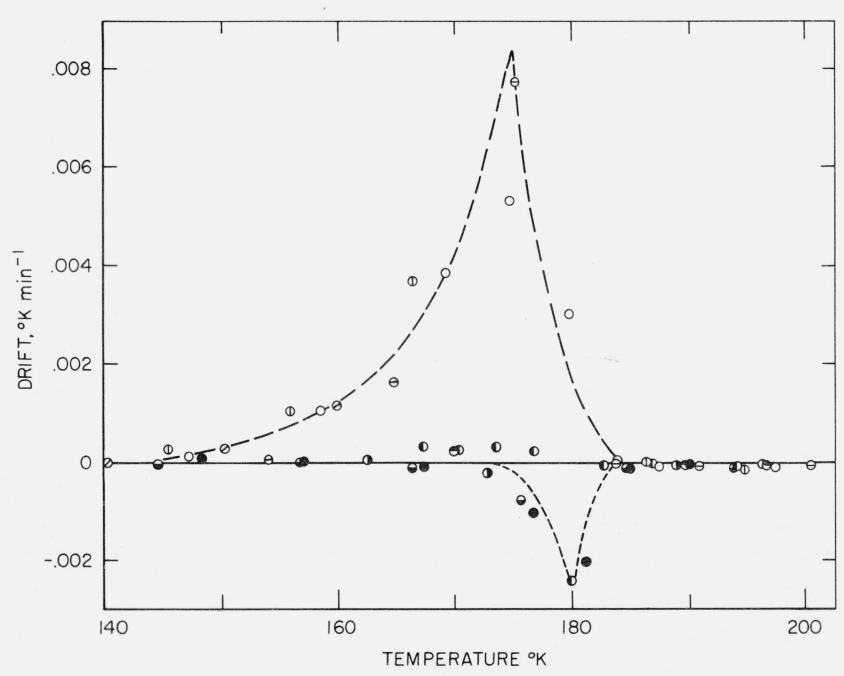

FIGURE 5. Calorimeter drifts for diethyl phthalate glasses in glass transformation temperature region.

Open and barred circles represent quenched glasses. Shaded circles represent annealed glasses. the annealed and the quenched glasses respectively at temperatures approaching the glass transformation. (Warm) drifts set in for the quenched glass when the temperature rises above $145^{\circ} \mathrm{K}$. This shows that the molecular configurations are starting to change at such temperatures. However, for the annealed glass, the temperature must rise above $170{ }^{\circ} \mathrm{K}$ before (cold) drifts set in. Therefore the molecular configurations fixed in the annealed glass are maintained fixed up to this temperature. For the annealed glass, as compared with the quenched, one gains an additional $25^{\circ}$ of temperature range over which the measurement results are characteristic of the fixed molecular configurations existing well below the glass transformation.

\section{5. $\Delta c_{p}$}

The difference, $\Delta c_{p}$, between the heat capacities of the glass and of the equilibrium supercooled liquid, both extrapolated to an arbitrarily specified glass transformation temperature, is utilized in certain considerations of the glass transformation process [25]. The precise specification of the heat capacity of the glass to be used in obtaining this difference is discussed in reference [24]. Wunderlich [26] has shown that for most glass-forming substances $\Delta c_{p}$ has a value of $11.3 \pm 2.1$ joule per degree per specifically defined material unit designated as a "bead." In using $\Delta c_{p}$ it is usually assumed as a first approximation that the quantity is independent of temperature, though this is well recognized as a crude approximation.

From the present work, $\Delta c_{p}$ for diethyl phthalate is evaluated as $115 \pm 3$ joule per degree and mole at $180{ }^{\circ} \mathrm{K}$. Usual criteria suggest seven beads per molecule for diethyl phthalate. On this basis $\Delta c_{p}$ would be $16.4 \pm 0.4$ joule per degree and mole. To bring the value within the limits mentioned above, it would be necessary to assume at least nine beads per molecular for diethyl phthalate. The higher value could be rationalized by assuming that the phthalyl group is not made completely rigid by conjugation resonance effects. The observed temperature derivative of $\Delta c_{p}$ for diethyl phthalate at $180{ }^{\circ} \mathrm{K}$ is 1.0 joule per degree, degree and mole, or about 1 percent of the value itself. This indicates the level of validity of the temperature independence approximation.

\section{References}

[1] K. F. Sterrett, D. H. Blackburn, A. B. Bestul, S. S. Chang, and J. Horman, J. Res. NBS 69C (Engr. and Instr.) No. 1, 19 (1965).

[2] P. A. Small, K. W. Small, and P. Cowley, Trans. Faraday Soc. 44, 810 (1948).

[3] G. T. Furukawa and M. Reilly, J. Res. NBS 69A (Phys. and Chem.) No. 1, 5 (1965).

[4] H. M. Roder, J. Res. NBS 69A (Phys. and Chem.) No. 6, 527 (1965).

[5] cf., e.g., G. O. Jones, Glass, p. 49 (John Wiley \& Sons, Inc., New York, N.Y., 1956).

[6] G. S. Parks, S. B. Thomas, and D. W. Light, J. Chem. Phys. 4, 64 (1936).

[7] C. T. Anderson, J. Am. Chem. Soc. 59, 1036 (1937). 
[8] E. F. Westrum, Jr. and G. Grenier, J. Am. Chem. Soc. 79 , 1799 (1957)

[9] E. F. Westrum, Jr., V International Congress on Glass, Paris, 1956, VII-6.

[10] W. P. White, Am. J. Sci. 47, 1 (1919).

[11] O. L. Anderson, J. Phys. Chem. Solids 12, 41 (1959).

[12] P. Flubacher, A. J. Leadbetter, J. A. Morrison, and B. P. Stoicheff, J. Phys. Chem. Solids 12, 53 (1959).

[13] H. B. Rosenstock, J. Phys. Chem. Solids 23, 659 (1962).

[14] R. S. Craig, C. W. Massena and R. M. Mallya, J. Appl. Phys. 36, 108 (1965).

[15] E. F. Westrum, Jr., unpublished data.

[16] F. Simon and F. Lange, Z. Physik 38, 227 (1926).

[17] W. Reese and J. E. Tucker, Bull. Am. Phys. Soc. 10, 323 (1965).

[18] O. L. Anderson and G. J. Dienes, in Non-Crystalline Solids, p. 453, V. D. Frechette, ed. (John Wiley \& Sons, Inc., New York, N.Y., 1960).
[19] W. Reese, J. Appl. P̈hys. 37, 3959 (1966).

[20] S. H. Glarum, J. Chem. Phys. 33, 639 (1960).

[21] B. I. Hunt and J. G. Powles, Proc. Phys. Soc. 88, 513 (1966).

[22] P. G. Klemens, in Non-Crystalline Solids, p. 508, V. D. Frechette, ed. (John Wiley \& Sons, Inc., New York, N.Y., 1960).

[23] P. G. Klemens, J. G. Castle and D. W. Feldman, Phys. Chem. Glass 5, 104 (1964).

[24] S. S. Chang, A. B. Bestul, and J. A. Horman, Proc. VII International Congress on Glass, Brussels, 1965, Gordon and Breach (New York) 1966, p. 26-1.3.1.

[25] cf., e.g., R. O. Davies and G. O. Jones, Proc. Roy Soc. A217, 26 (1953).

[26] B. Wunderlich, J. Phys. Chem. 64, 1052 (1960).

(Paper 71A4-461) 